\title{
GMR
}

\section{Propofol inhibits proliferation and accelerates apoptosis of human gastric cancer cells by regulation of microRNA-451 and MMP-2 expression}

\author{
Z. Peng and Y. Zhang \\ Department of General Surgery, \\ PLA General Hospital and PLA Postgraduate Medical School, Beijing, China \\ Corresponding author: Z. Peng \\ E-mail: zhengpengdr@163.com \\ Genet. Mol. Res. 15 (2): gmr.15027078 \\ Received June 24, 2015 \\ Accepted October 30, 2015 \\ Published April 4, 2016 \\ DOI http://dx.doi.org/10.4238/gmr.15027078
}

\begin{abstract}
Propofol is an extensively used intravenous anesthetic agent. The aim of the present study was to evaluate the effects of propofol on the behavior of human gastric cancer cells and the molecular mechanisms associated with this activity. The effects of propofol on proliferation and apoptosis in the SGC-7901 gastric cancer cell line were detected by an MTT assay and measurement of caspase- 3 activity. The protein expression levels of matrix metalloproteinase-2 (MMP-2) were detected by western blotting. Reverse transcription-quantitative polymerase chain reaction was conducted to evaluate the effect of propofol treatment on microRNA (miR)451 expression levels and an miR-451 precursor was used to evaluate whether miR-451 overexpression affects MMP-2 expression levels. In addition, the effect of miR-451 on propofol-induced antitumor activity was evaluated using anti-miR-451. Propofol significantly elevated miR-451 expression levels, inhibited SGC-7901 cell proliferation, and promoted apoptosis. Propofol also efficiently reduced MMP-2 protein expression levels. Furthermore, miR-451 overexpression reduced MMP-2 protein
\end{abstract}


expression levels. In addition, neutralization of miR-451 by anti-miR-451 antibody reversed the effect of propofol on cell proliferation and apoptosis and upregulated MMP-2 expression in the SGC-7901 cells. Propofol effectively inhibited proliferation and induced apoptosis in gastric cancer cells, which was partly owing to the downregulation of MMP-2 expression by miR-451.

Key words: Propofol; Gastric cancer; miR-451; MMP-2; Proliferation; Apoptosis

\section{INTRODUCTION}

Gastric cancer is the second leading cause of cancer-related mortality worldwide and is most likely to remain a predominant cause of mortality in the near future. In China, patients with gastric cancer are commonly diagnosed at an advanced clinical stage, with evident lymphatic tumor dissemination (Bandres et al., 2009). The five-year survival rate is approximately $60 \%$ for patients with localized disease but only $2 \%$ for those with metastatic disease (Rojo et al., 2006). Many studies have identified a variety of molecules associated with the development of gastric cancer. Among these molecules, matrix metalloproteinases (MMPs) are important as they degrade extracellular matrix proteins. The expression levels of MMP-2 have been reported to be increased in gastric cancer, and this increase is associated with advanced tumor stage and poor survival (Alakus et al., 2008; Ma et al., 2011). MicroRNAs (miRNAs) are a class of single-stranded, highly conserved, small non-coding RNA molecules of $\sim 22$ nucleotides in length. miRNAs regulate gene expression levels through binding to the 3'-untranslated region of target mRNAs, resulting in mRNA degradation or inhibition of translation (Zhao et al., 2013). miRNAs contribute to the majority of basic biological processes, such as development, differentiation, apoptosis, and cell proliferation. In addition, miRNAs may function as either oncogenes or tumor suppressors by specifically regulating the expression levels of target genes (Zhang et al., 2007). Aberrant miRNA expression levels and mutations in miRNA genes involved in gastric cancer have been well described (Gao et al., 2013; Stenholm et al., 2013). In terms of miR-451, it has been confirmed to be downregulated in many types of human malignancies, including gastric cancer (Kovalchuk et al., 2008; Bandres et al., 2009; Bian et al., 2011; Tian et al., 2012). Furthermore, an enforced increase in the miR-451 expression levels in gastric cancer cells was shown to reduce cell proliferation and increase cell sensitivity to radiotherapy (Bandres et al., 2009).

Propofol (2,6-diisopropylphenol) is a commonly used intravenous anesthetic. Increasing evidence has indicated that propofol exhibits the ability to influence the motility, proliferation, and invasion of cancer cells in vitro and in vivo (Mammoto et al., 2002; Miao et al., 2010; Altenburg et al., 2011; Zhang et al., 2013a). Therefore, propofol may be a particularly suitable anesthetic for the perioperative phase of cancer surgery (Inada et al., 2011). However, to the best of our knowledge, no available information exists regarding the antitumor action of propofol in gastric cancer. The aim of the present study was to evaluate the effect of propofol on the behavior of human gastric cancer cells and the molecular mechanisms associated with this activity.

\section{MATERIAL AND METHODS}

\section{Cell culture and reagents}

The SGC-7901 human gastric cancer cell line was obtained from the Shanghai Institute 
of Cell Biology, Chinese Academy of Sciences (Shanghai, China) and cultured in Dulbecco's modified Eagle's medium (Invitrogen Life Sciences, Carlsbad, CA, USA) supplemented with 10\% fetal bovine serum (Sigma-Aldrich, St. Louis, MO, USA), $2 \mathrm{mM}$ glutamine, $100 \mathrm{U} / \mathrm{mL}$ penicillin and $100 \mathrm{mg} / \mathrm{mL}$ streptomycin at $37^{\circ} \mathrm{C}$ in $5 \% \mathrm{CO}_{2}$ and $95 \%$ atmospheric air. Propofol was purchased from Sigma-Aldrich and dissolved in dimethylsulfoxide (DMSO; Sigma-Aldrich) for in vitro analysis. The MMP-2 enzyme-linked immunosorbent assay (ELISA) kit was purchased from R\&D Systems (Abingdon, UK). Polyclonal antibodies, including anti- $\beta$-actin and anti-MMP-2 were purchased from Santa Cruz Biotechnology (Santa Cruz, CA, USA).

\section{Cell viability assay}

The quantitative colorimetric assay with 3-(4,5-dimethylthiazol-2-yl)-2,5-di-phenyltetrazolium (MTT; Sigma-Aldrich) was performed on 96-well plates to measure cell viability. Briefly, subsequent to propofol treatment for the indicated lengths of time, $20 \mu \mathrm{L} 5 \mathrm{mg} / \mathrm{mL}$ MTT was added to each corresponding test well and incubated at $37^{\circ} \mathrm{C}$ for $4 \mathrm{~h}$ in $5 \% \mathrm{CO}_{2}$ and $95 \%$ atmospheric air. The MTT solution was subsequently replaced with $200 \mu \mathrm{L}$ DMSO in order to dissolve the colored formazan crystals. The absorbance of each aliquot was read at $570 \mathrm{~nm}$ with a multidetection microplate reader (BMG Labtech, Durham, NC, USA). The experiments were independently repeated three times and the values are reported as means \pm standard deviation.

\section{Apoptosis analysis by Hoechst 33258 staining and caspase- 3 activity measurement}

Changes in nuclear morphology were evaluated by Hoechst 33258 fluorescence staining. The SGC-7901 gastric cancer cells were cultured on 24-well plates to $85 \%$ confluence and then treated with different concentrations of propofol for $48 \mathrm{~h}$ at $37^{\circ} \mathrm{C}$. The cells were washed in ice cold phosphate-buffered saline (PBS), fixed with $4 \%$ formaldehyde in PBS for $15 \mathrm{~min}$, and stained with $10 \mu \mathrm{g} / \mathrm{mL}$ Hoechst 33258 (Sigma-Aldrich) for $5 \mathrm{~min}$ at room temperature. Apoptosis was assessed by the observation of condensed or fragmented nuclei.

The activity of caspase-3, a key enzyme in the modulation of apoptotic cascades, was determined to further detect cell apoptosis at the molecular level. Briefly, cells were cultivated on 96-well plates, treated with drugs as mentioned in the figure legends, and assayed with colorimetric assay kits (Promega Corporation, Madison, WI, USA) according to the manufacturer instructions.

\section{Gelatin zymography assays}

To assess MMP-2 activity in SGC-7901 cells, a gelatin zymography assay was performed. Briefly, the SGC-7901 cells were incubated on 24-well plates for $24 \mathrm{~h}$. Following serum starvation for $24 \mathrm{~h}$, the cells were treated with different concentrations of propofol for the indicated time periods. The supernatants were collected, centrifuged at $3000 \mathrm{~g}$ for $10 \mathrm{~min}$, and the protein concentration was determined using a bicinchoninic acid (BCA) protein assay kit (Beyotime Biotech, Jiangsu, China). Proteins $(40 \mu \mathrm{g})$ were loaded onto a gel $(8 \%$ polyacrylamide gels containing $1 \mathrm{mg} / \mathrm{mL}$ gelatin) and separated by electrophoresis. The gels were washed for 30 min twice in $2 \%(v / v)$ Triton X-100 (SigmaAldrich) to remove sodium dodecyl sulfate (SDS), and were then developed overnight at $37^{\circ} \mathrm{C}$ in Zymogram incubation buffer (10 $\mathrm{mM} \mathrm{CaCl}_{2}, 0.01 \% \mathrm{NaN}_{3}$, and $40 \mathrm{mM}$ Tris-HCl), pH 8.0, and stained with Coomassie blue R250 solution. The MMP-2 protein was identified according to molecular weight. 


\section{miRNA extraction and quantitative real-time PCR}

miRNA extraction was conducted according to the standard Trizol (Invitrogen) protocol. The quantification of miR-451 level was performed by real-time PCR using TransStart ${ }^{\mathrm{TM}}$ SYBR Green qPCR Supermix (TransGen Biotech, Beijing, China) and U6 small nuclear RNA was used as an internal control. The primers utilized for real-time PCR analysis were as follows: (miR-451) forward, 5'-TCGAGGATCCCTGGGTACCCCACCTCCAGAGCCT-3' and reverse, 5'-TCGAGCTAGCAAAATGTACCCTTTCCCCCAACCCCATT-3'; (U6) forward, 5'-CTC GCT TCG GCA GCA CA-3' and reverse, 5'-AAC GCT TCA CGA ATT TGC GT-3'. Relative quantification of gene expression was performed with the Applied Biosystems 7300 Real-Time PCR System and data analysis was carried out using the $2^{-\Delta \Delta C t}$ cycle threshold method.

\section{Western blot analysis}

For western blotting, the SGC-7901 cells were lysed in an ice-cold radioimmunoprecipitation buffer containing $10 \mathrm{mM}$ Tris, $\mathrm{pH} 8.0,150 \mathrm{mM} \mathrm{NaCl}, 10 \%$ glycerol, 1\% NP-40, $5 \mathrm{mM}$ EDTA, and protease inhibitor cocktail. The homogenates were then centrifuged at $13,200 \mathrm{~g}$ for $20 \mathrm{~min}$ at $4^{\circ} \mathrm{C}$ and the supernatant was aliquoted and frozen at $-80^{\circ} \mathrm{C}$. The quantification of total protein was performed using the BCA protein assay kit. Quantities of $30 \mu \mathrm{g}$ total protein extract were separated by $12 \%$ SDS-PAGE and blotted onto nitrocellulose membranes (Millipore, Billerica, MA, USA). The membranes were incubated with $5 \%$ non-fat milk for $1 \mathrm{~h}$ at room temperature. The membranes were then incubated with affinity purified rabbit anti-MMP-2 (1:300; Santa Cruz Biotechnology) or $\beta$-actin (1:2000; Santa Cruz Biotechnology) antisera at $4^{\circ} \mathrm{C}$ overnight. Following three washes in Trisbuffered saline/Tween-20, the membranes were incubated for $2 \mathrm{~h}$ with peroxidase-labeled goat antirabbit lgG (1:5000; Santa Cruz Biotechnology). Immunolabeled protein bands were detected with an enhanced chemiluminesecence kit (Applygen Technologies Inc., Beijing, China) and exposed on an $X$-ray film. $\beta$-actin served as a reference for relative quantification. Following development, the band intensities were quantified using the Quantity One software (Bio-Rad, Hercules, CA, USA).

\section{Cell transfection procedures}

miR-451 precursor (100 nM) or anti-miR451 (Ambion, Carlsbad, CA, USA) was added to the cells to overexpress or knockdown miR-451 by co-transfection with Lipofectamine 2000 (Invitrogen Life Sciences) in antibiotic-free medium, at 30-50\% confluency, on 60-mm dishes for 24 h. The cells were subsequently treated with propofol.

\section{Statistical analysis}

Analysis of variance and the Student $t$-test were performed with the SPSS software (version 17.0; SPSS Inc., Chicago, IL, USA) and the data are reported as means \pm standard deviation. $\mathrm{P}<0.05$ and $\mathrm{P}<0.01$ were considered to indicate a statistically significant difference.

\section{RESULTS}

\section{Propofol inhibits cell proliferation and accelerates apoptosis}

Propofol treatment significantly reduced the proliferation of the SGC-7901 human gastric 
cancer cells in a dose- and time-dependent manner as measured by an MTT assay (Figure 1A). Specifically, 5 and $10 \mu \mathrm{g} / \mathrm{mL}$ propofol markedly inhibited SGC-7901 cell growth at 48 and $72 \mathrm{~h}$. The apoptotic effect of propofol was assessed by Hoechest 33258 staining and caspase-3 activity determination after $48 \mathrm{~h}$ of treatment, as shown in Figure 1B and C, respectively. An increased rate of apoptosis was observed in SGC-7901 cells following exposure to propofol for $48 \mathrm{~h}$. In conclusion, propofol inhibited proliferation and promoted apoptosis in SGC-7901 cells.

A
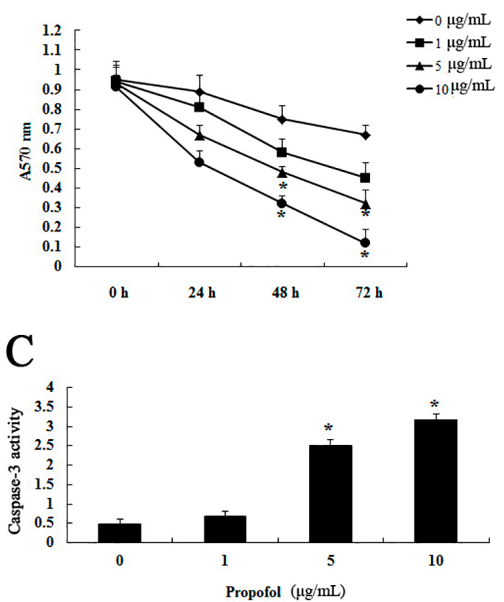

B

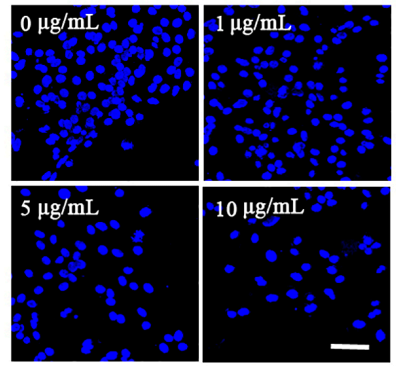

Figure 1. Propofol inhibits cell proliferation and promotes apoptosis. Treatment with propofol prevented cell proliferation (A) and promotes apoptosis (B and C) in a dose-dependent manner in human gastric cancer cell line SGC-7901. *P < 0.01 versus the control group without propofol treatment.

\section{Propofol inhibits MMP-2 activity}

Subsequent experiments were conducted to investigate the effect of propofol on MMP-2 activity in SGC-7901 cells. Gelatin zymography analysis revealed that propofol treatment dosedependently suppressed MMP-2 activity ( $<<0.01)$, as shown in Figure $2 \mathrm{~A}$.

To confirm propofol-induced MMP-2 inhibition, MMP-2 protein expression levels were evaluated by western blot analysis. As shown in Figures 2B and C, significant reduction in MMP-2 protein expression levels was observed in cells exposed to $5 \mu \mathrm{g} / \mathrm{mL}$ propofol compared with that in the control cells $(P<0.01)$, which was consistent with the observed results of MMP-2 activity. In addition, propofol was found to inhibit MMP-2 protein expression in a dose-dependent manner, with a $56.41 \%$ reduction at $5 \mu \mathrm{g} / \mathrm{mL}$ and $76.50 \%$ reduction at $10 \mu \mathrm{g} / \mathrm{mL}$.

\section{Propofol activates miR-451 expression}

Notably, propofol treatment dose-dependently increased miR-451 expression levels in SGC7901 cells, as shown in Figure 3. Specifically, the miR-451 expression levels increased 2.64-fold by $5 \mu \mathrm{g} / \mathrm{mL}$ propofol treatment, with a 3.72-fold increase following $10 \mu \mathrm{g} / \mathrm{mL}$ propofol treatment, significantly higher than the relative miR-451 expression levels in the control cells $(P<0.01)$. 
A

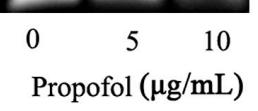

B

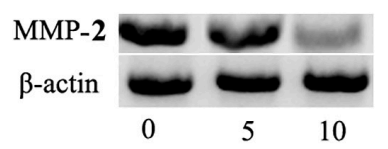

Propofol $(\mu \mathrm{g} / \mathrm{mL})$
$\mathrm{C}$

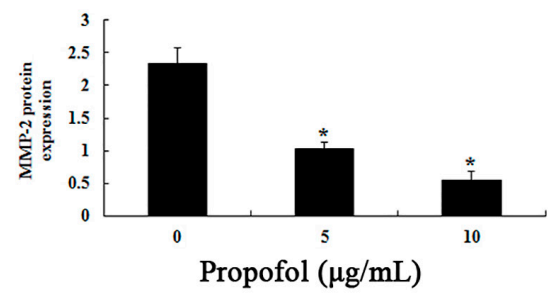

Figure 2. Propofol downregulates MMP-2 activity. MMP-2 activity dose-dependently reduced in SGC-7901 cells after exposure to propofol for $24 \mathrm{~h}$ by gelatin zymography assays (A). The protein expression of MMP-2 in SGC-7901 cells decreased after propofol treatment (B). Statistical analysis of MMP-2 protein levels were conducted $(\mathbf{C})$. ${ }^{*} \mathrm{P}<0.01$ versus the control group without propofol treatment.

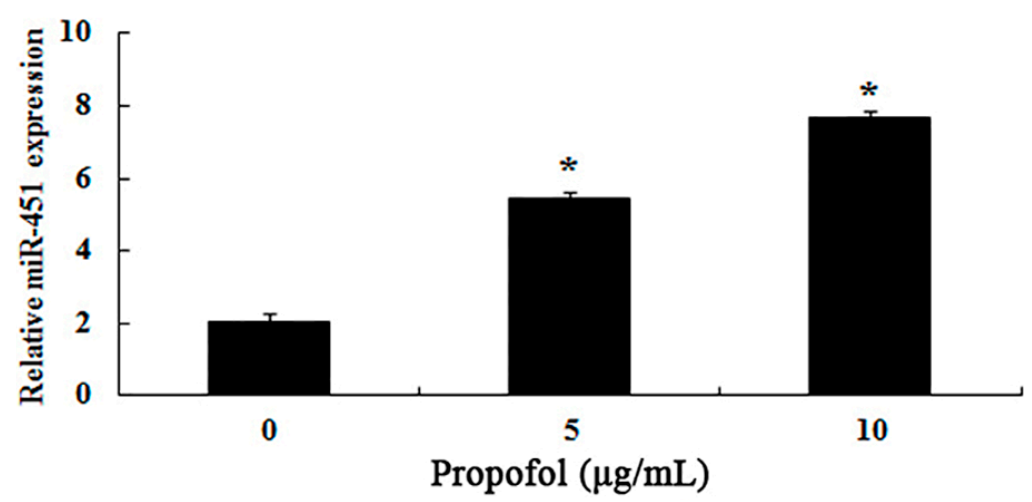

Figure 3. Propofol activates miR-451 expression. Administration of propofol significantly augmented miR-451 expression in a dose-dependent way. ${ }^{*} \mathrm{P}<0.01$ versus the control group without propofol treatment.

\section{Overexpression of miR-451 reduces MMP-2 expression levels}

The effect of miR-451 on MMP-2 expression levels in SGC-7901 cells was also investigated. miR-451 expression levels were determined by RT-qPCR analysis following transfection with the miR-451 precursor. The results demonstrated that the miR-451 precursor significantly increased miR-451 expression levels in SGC-7901 cells, as shown in Figure 4A $(P<0.01)$, and MMP-2 expression levels were subsequently reduced because of overexpression of miR-451 (Figure 4B).

\section{Anti-miR-451 reverses the effect of propofol}

Anti-miR-451 was selected to assess the role of miR-451 in propofol-induced changes in SGC-7901 cells. RT-qPCR analysis revealed that the anti-miR-451 antibody significantly reduced miR-451 expression levels, suggesting the efficient introduction of anti-miR-451 antibody into SGC7901 cells (Figure $5 \mathrm{~A} ; \mathrm{P}<0.01$ ). This inhibitor markedly reversed the prevention of cell proliferation and the induction of apoptosis caused by propofol (Figure 5B, C, and D). The inhibitory effect of 
propofol on MMP-2 expression levels was also markedly reversed following transfection with antimiR-451 antibody in SGC-7901 cells (Figure 5E).

A

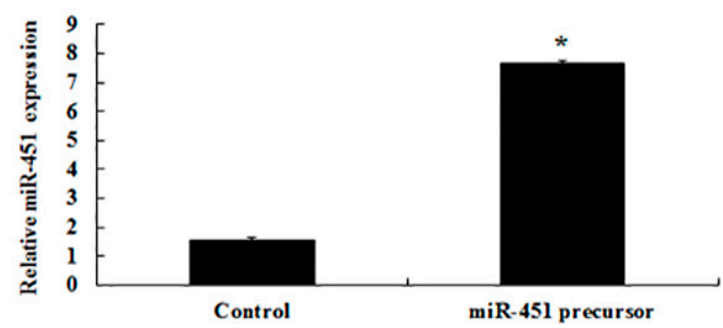

B

\section{MMP-2}

\section{$\beta$-actin}

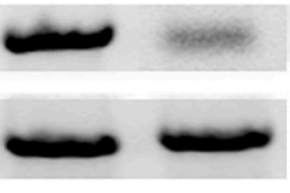

\section{Control miR-451 precursor}

Figure 4. Overexpression of miR-451 can restrain MMP-2 expression. The expression of miR-451 was obviously elevated after transfection with miR-451 precursor (A). The results of western blot showed that transfection of miR-451 precursor diminished MMP-2 protein expression (B). *P $<0.01$ versus the control group.
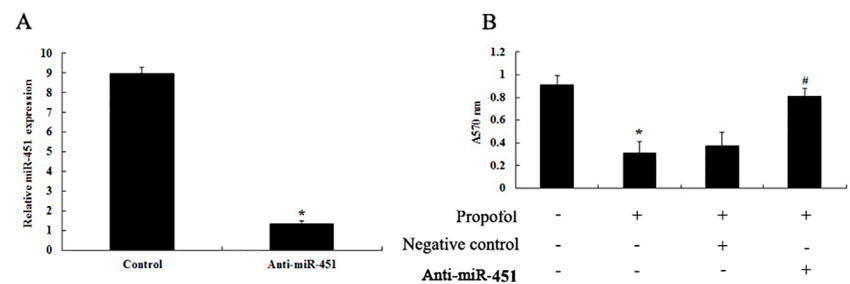

C

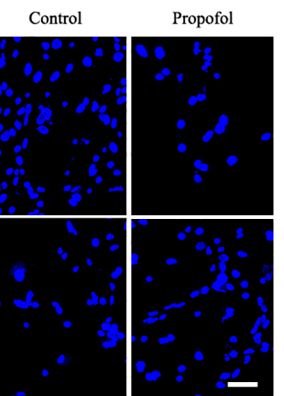

D

$\mathrm{D}$

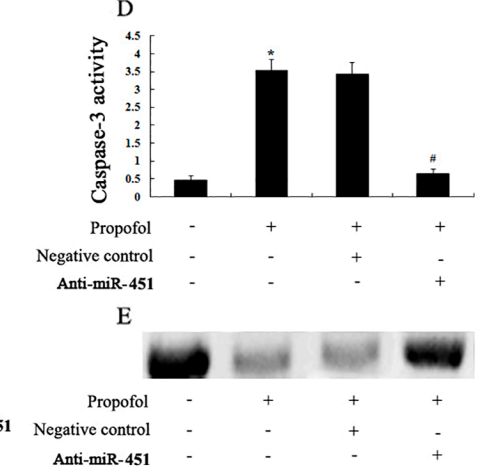

Figure 5. Anti-miR-451 can reverse the effect of propofol. Expression of miR-451 decreased after transfection with anti-miR-451 precursor (A). Anti-miR-451 evidently promoted cell proliferation (B) and inhibited cell apoptosis (C and D) after treatment with propofol. ${ }^{*} \mathrm{P}<0.01$ compared with the control group without propofol treatment and ${ }^{\#} \mathrm{P}<0.01$ compared with propofol-treated group transfected with negative control. Western blot analysis indicated that antimiR-451 significantly increased MMP-2 protein expression in SGC-7901 cells after propofol treatment (E).

\section{DISCUSSION}

Gastric cancer remains a frequent cause of mortality worldwide since effective options for gastric cancer treatment are limited. In the present study, the effects of propofol treatment on the behavior of gastric cancer cells were evaluated, and propofol was found to inhibit SGC-7901 cell 
proliferation and promote apoptosis. These results are consistent with those of other studies. For example, Zhang et al. (2013a) reported that propofol inhibited the growth and invasion and induced apoptosis of hepatocellular carcinoma cells. Mammoto et al. (2002) demonstrated that clinically relevant concentrations of propofol decreased the invasion ability of human cancer cells (HeLa, HT1080, HOS, and RPMI-7951). Miao et al. (2010) reported that propofol inhibited invasion of LOVO colon cancer cells. Therefore, propofol may be a more effective agent than other anesthetics in cancer surgery (Siddiqui et al., 2005; Inada et al., 2011; Wu et al., 2013).

To clarify the mechanism involved in the propofol-mediated SGC-7901 cell suppression, the effect of propofol on miR-451 and MMP-2 expression levels in the cells was examined. Propofol was observed to stimulate the expression of miR-451 in SGC-7901 cells. Overexpression of miR-451 inhibited MMP-2 protein expression. Notably, neutralizing miR-451 with an anti-miR-451 antibody reversed the effect of propofol on the proliferation and apoptosis of SGC-7901 cells and upregulated MMP-2 expression. These results suggest that the antitumor function of propofol on gastric cancer cells may be partly due to miR-451-mediated downregulation of MMP-2. Previous studies have demonstrated that anesthetic treatment may result in numerous changes in miRNA expression levels, and that the miRNA expression pattern was specific for each anesthetic (Ishikawa et al., 2012; Zhang et al., 2013b). Ishikawa et al. (2012) also revealed increased miR-451 expression levels in healthy rat livers following propofol treatment. However, the detailed mechanisms of how propofol influences miRNA expression levels remain unclear and further clarification is required.

One important step in tumor invasion and metastasis is the degradation of collagen IV, a basic element of basement membranes. MMP-2, also known as gelatinase A or 72-kDa collagenase IV, is a member of the MMP family and is able to degrade gelatin and type IV collagen, suggesting that MMP-2 is involved in tumor metastasis and may be of prognostic significance in the survival of cancer patients. Overexpression of MMP-2 in gastric cancer is responsible for increased tumor invasiveness and poor prognosis (Alakus et al., 2008). miR-451 has been identified as one of the most lowly expressed miRNAs in various tumors, including lung cancer (Wang et al., 2011), breast cancer (Kovalchuk et al., 2008), glioma (Tian et al. 2012), head and neck squamous cell carcinoma (Hui et al., 2010), and gastric cancer (Bandres et al., 2009). In those cases, miR-451 was always observed to act as a tumor suppressor. Nan et al. (2010) verified the regulatory function of miR451 on MMP-2 expression. However, miRNAs may function in accordance with the combinatorial circuits model, in which a single miRNA targets multiple mRNAs and several coexpressed miRNAs may target a single mRNA. Therefore, the potential regulatory circuit associated with miR-451 is vast and MMP-2 is only one important node in a large network. The identification of further miR451 molecular characteristics may aid in explaining the antitumor function of miR-451 in various human malignancies.

In conclusion, the present study indicates that propofol inhibits the proliferation and induces apoptosis of gastric cancer cells by upregulating miR-451 and downregulating MMP-2 expression. Further studies in animal models and clinical trials are required to elucidate the exact effect of propofol on gastric cancer.

\section{REFERENCES}

Alakus H, Grass G, Hennecken JK, Bollschweiler E, et al. (2008). Clinicopathological significance of MMP-2 and its specific inhibitor TIMP-2 in gastric cancer. Histol. Histopathol. 23: 917-923.

Altenburg JD, Harvey KA, McCray S, Xu Z, et al. (2011). A novel 2,6-diisopropylphenyl-docosahexaenoamide conjugate induces apoptosis in T cell acute lymphoblastic leukemia cell lines. Biochem. Biophys. Res. Commun. 411: 427-432. http://dx.doi.org/10.1016/j.bbrc.2011.06.172 
Bandres E, Bitarte N, Arias F, Agorreta J, et al. (2009). microRNA-451 regulates macrophage migration inhibitory factor production and proliferation of gastrointestinal cancer cells. Clin. Cancer Res. 15: 2281-2290.http://dx.doi.org/10.1158/1078-0432. $\underline{\text { CCR-08-1818 }}$

Bian HB, Pan X, Yang JS, Wang ZX, et al. (2011). Upregulation of microRNA-451 increases cisplatin sensitivity of non-small cell lung cancer cell line (A549). J. Exp. Clin. Cancer Res. 30: 20.http://dx.doi.org/10.1186/1756-9966-30-20

Gao M, Yin H and Fei ZW (2013). Clinical application of microRNA in gastric cancer in Eastern Asian area. World J. Gastroenterol. 19: 2019-2027.http://dx.doi.org/10.3748/wjg.v19.i13.2019

Hui AB, Lenarduzzi M, Krushel T, Waldron L, et al. (2010). Comprehensive MicroRNA profiling for head and neck squamous cell carcinomas. Clin. Cancer Res. 16: 1129-1139.http://dx.doi.org/10.1158/1078-0432.CCR-09-2166

Inada T, Kubo K and Shingu K (2011). Possible link between cyclooxygenase-inhibiting and antitumor properties of propofol. J. Anesth. 25: 569-575.http://dx.doi.org/10.1007/s00540-011-1163-y

Ishikawa M, Tanaka S, Arai M, Genda Y, et al. (2012). Differences in microRNA changes of healthy rat liver between sevoflurane and propofol anesthesia. Anesthesiology 117: 1245-1252.http://dx.doi.org/10.1097/ALN.0b013e3182746676

Kovalchuk O, Filkowski J, Meservy J, Inytskyy Y, et al. (2008). Involvement of microRNA-451 in resistance of the MCF-7 breast cancer cells to chemotherapeutic drug doxorubicin. Mol. Cancer Ther. 7: 2152-2159.http://dx.doi.org/10.1158/1535-7163. MCT-08-0021

Ma LJ, Li YG, Huang L, Han M, et al. (2011). [Expression of LOX and MMP-2 in gastric cancer tissue and the effects of LOX and MMP-2 on tumor invasion and metastasis]. Zhonghua Zhong Liu Za Zhi 33: 37-41.

Mammoto T, Mukai M, Mammoto A, Yamanaka Y, et al. (2002). Intravenous anesthetic, propofol inhibits invasion of cancer cells. Cancer Lett. 184: 165-170.http://dx.doi.org/10.1016/S0304-3835(02)00210-0

Miao Y, Zhang Y, Wan H, Chen L, et al. (2010). GABA-receptor agonist, propofol inhibits invasion of colon carcinoma cells. Biomed. Pharmacother. 64: 583-588.http://dx.doi.org/10.1016/j.biopha.2010.03.006

Nan Y, Han L, Zhang A, Wang G, et al. (2010). MiRNA-451 plays a role as tumor suppressor in human glioma cells. Brain Res. 1359: 14-21.http://dx.doi.org/10.1016/j.brainres.2010.08.074

Rojo F, Tabernero J, Albanell J, Van Cutsem E, et al. (2006). Pharmacodynamic studies of gefitinib in tumor biopsy specimens from patients with advanced gastric carcinoma. J. Clin. Oncol. 24: 4309-4316.http://dx.doi.org/10.1200/JCO.2005.04.2424

Siddiqui RA, Zerouga M, Wu M, Castillo A, et al. (2005). Anticancer properties of propofol-docosahexaenoate and propofoleicosapentaenoate on breast cancer cells. Breast Cancer Res. 7: R645-R654.http://dx.doi.org/10.1186/bcr1036

Stenholm L, Stoehlmacher-Williams J, AI-Batran SE, Heussen N, et al. (2013). Prognostic role of microRNA polymorphisms in advanced gastric cancer: a translational study of the Arbeitsgemeinschaft Internistische Onkologie (AIO). Ann. Oncol. 24: 2581-2588.http://dx.doi.org/10.1093/annonc/mdt330

Tian Y, Nan Y, Han L, Zhang A, et al. (2012). MicroRNA miR-451 downregulates the PI3K/AKT pathway through CAB39 in human glioma. Int. J. Oncol. 40: 1105-1112.

Wang R, Wang ZX, Yang JS, Pan X, et al. (2011). MicroRNA-451 functions as a tumor suppressor in human non-small cell lung cancer by targeting ras-related protein 14 (RAB14). Oncogene 30: 2644-2658.http://dx.doi.org/10.1038/onc.2010.642

Wu RS, Liu KC, Tang NY, Chung HK, et al. (2013). cDNA microarray analysis of the gene expression of murine leukemia RAW 264.7 cells after exposure to propofol. Environ. Toxicol. 28: 471-478.http://dx.doi.org/10.1002/tox.20742

Zhang B, Pan X, Cobb GP and Anderson TA (2007). microRNAs as oncogenes and tumor suppressors. Dev. Biol. $302: 1-12$. http://dx.doi.org/10.1016/j.ydbio.2006.08.028

Zhang J, Wu GQ, Zhang Y, Feng ZY, et al. (2013a). Propofol induces apoptosis of hepatocellular carcinoma cells by upregulation of microRNA-199a expression. Cell Biol. Int. 37: 227-232.http://dx.doi.org/10.1002/cbin.10034

Zhang J, Zhang D, Wu GQ, Feng ZY, et al. (2013b). Propofol inhibits the adhesion of hepatocellular carcinoma cells by upregulating microRNA-199a and downregulating MMP-9 expression. HBPD INT 12: 305-309.http://dx.doi.org/10.1016/ S1499-3872(13)60048-X

Zhao G, Cai C, Yang T, Qiu X, et al. (2013). MicroRNA-221 induces cell survival and cisplatin resistance through PI3K/Akt pathway in human osteosarcoma. PLoS One 8: e53906.http://dx.doi.org/10.1371/journal.pone.0053906 